
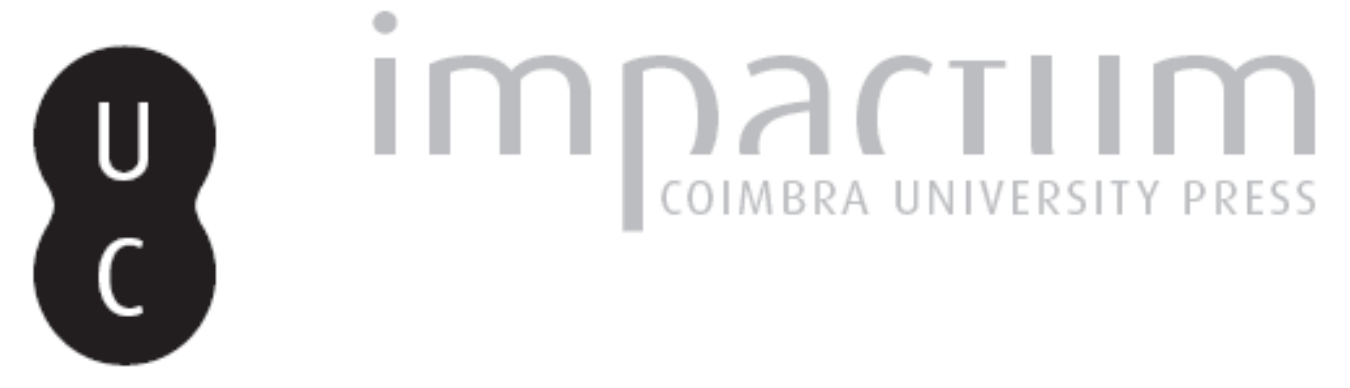

\title{
Íbico, Schiller: as asas eternas do canto
}

\section{Autor(es): $\quad$ Barroso, Maria do Sameiro}

Publicado por: Associação Portuguesa de Estudos Clássicos; Instituto de Estudos

URL $\quad$ URistente: $\quad$ URIttp://hdl.handle.net/10316.2/30402

DOI: $\quad$ DOl:http://dx.doi.org/10.14195/0872-2110_52_15

Accessed : $\quad$ 26-Apr-2023 16:17:47

A navegação consulta e descarregamento dos títulos inseridos nas Bibliotecas Digitais UC Digitalis, UC Pombalina e UC Impactum, pressupõem a aceitação plena e sem reservas dos Termos e Condições de Uso destas Bibliotecas Digitais, disponíveis em https://digitalis.uc.pt/pt-pt/termos.

Conforme exposto nos referidos Termos e Condições de Uso, o descarregamento de títulos de acesso restrito requer uma licença válida de autorização devendo o utilizador aceder ao(s) documento(s) a partir de um endereço de IP da instituição detentora da supramencionada licença.

Ao utilizador é apenas permitido o descarregamento para uso pessoal, pelo que o emprego do(s) título(s) descarregado(s) para outro fim, designadamente comercial, carece de autorização do respetivo autor ou editor da obra.

Na medida em que todas as obras da UC Digitalis se encontram protegidas pelo Código do Direito de Autor e Direitos Conexos e demais legislação aplicável, toda a cópia, parcial ou total, deste documento, nos casos em que é legalmente admitida, deverá conter ou fazer-se acompanhar por este aviso.

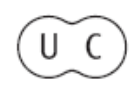




\section{Boletim de}

\section{Estudos Clássicos}

Associação Portuguesa de Estudos Clássicos Instituto de Estudos Clássicos

Coimbra

Dezembro de 2009 


\section{ÍBICO, SCHILLER \\ As ASAS ETERnAS do CANTO}

\section{Die Kraniche des Ibykus}

Zum Kampf der Wagen und Gesänge,

Der auf Korinthus Landesenge

Der Griechen Stämme froh vereint, Zog Ibykus, der Götterfreund.

Ihm schenkte des Gesanges Gabe,

Der Lieder süßen Mund Apoll,

So wandert' er, an leichtem Stabe,

Aus Rhegium, des Gottes voll.

Schon winkt auf hohem Bergesrücken

Akrokorinth des Wandrers Blicken,

Und in Poseidons Fichtenhain

Tritt er mit frommem Schauder ein.

Nichts regt sich um ihn her, nur Schwärme

Von Kranichen begleiten ihn,

Die fernhin nach des Südens Wärme

In graulichtem Geschwader ziehn.

»Seid mir gegrüßt, befreundte Scharen!

Die mir zur See Begleiter waren, Zum guten Zeichen nehm ich euch, Mein Los, es ist dem euren gleich.

Von fernher kommen wir gezogen

Und flehen um ein wirtlich Dach.

Sei uns der Gastliche gewogen,

Der von dem Fremdling wehrt die Schmach!«

Und munter fördert er die Schritte, Und sieht sich in des Waldes Mitte, Da sperren, auf gedrangem Steg, Zwei Mörder plötzlich seinen Weg. 
Zum Kampfe muß er sich bereiten, Doch bald ermattet sinkt die Hand, Sie hat der Leier zarte Saiten, Doch nie des Bogens Kraft gespannt.

Er ruft die Menschen an, die Götter, Sein Flehen dringt zu keinem Retter, Wie weit er auch die Stimme schickt, Nicht Lebendes wird hier erblickt. "So muß ich hier verlassen sterben, Auf fremdem Boden, unbeweint, Durch böser Buben Hand verderben, Wo auch kein Rächer mir erscheint!«

Und schwer getroffen sinkt er nieder, Da rauscht der Kraniche Gefieder, Er hört, schon kann er nichts mehr sehn, Die nahen Stimmen furchtbar krähn. »Von euch, ihr Kraniche dort oben! Wenn keine andre Stimme spricht, Sei meines Mordes Klag’ erhoben!« Er ruft es, und sein Auge bricht.

Der nackte Leichnam wird gefunden, Und bald, obgleich entstellt von Wunden, Erkennt der Gastfreund in Korinth

Die Züge, die ihm teuer sind. »Und muß ich dich so wiederfinden, Und hoffte mit der Fichte Kranz Des Sängers Schläfe zu umwinden, Bestrahlt von seines Ruhmes Glanz!«

Und jammernd hören's alle Gäste, Versammelt bei Poseidons Feste, Ganz Griechenland ergreift der Schmerz, Verloren hat ihn jedes Herz, Und stürmend drängt sich zum Prytanen

Das Volk, es fordert seine Wut, 
Zu rächen des Erschlag'nen Manen, Zu sühnen mit des Mörders Blut.

Doch wo die Spur, die aus der Menge,

Der Völker flutendem Gedränge, Gelocket von der Spiele Pracht, Den schwarzen Täter kenntlich macht? Sind's Räuber, die ihn feig erschlagen? Tat's neidisch ein verborgner Feind? Nur Helios vermag's zu sagen, Der alles Irdische bescheint.

Er geht vielleicht mit frechem Schritte Jetzt eben durch der Griechen Mitte, Und während ihn die Rache sucht, Genießt er seines Frevels Frucht. Auf ihres eignen Tempels Schwelle Trotzt er vielleicht den Göttern, mengt Sich dreist in jene Menschenwelle, Die dort sich zum Theater drängt.

Denn Bank an Bank gedränget sitzen, Es brechen fast der Bühne Stützen, Herbeigeströmt von Fern und Nah, Der Griechen Völker wartend da, Dumpfbrausend wie des Meeres Wogen, Von Menschen wimmelnd, wächst der Bau, In weiter stets geschweiftem Bogen Hinauf bis in des Himmels Blau.

Wer zählt die Völker, nennt die Namen, Die gastlich hier zusammenkamen?

Von Theseus Stadt, von Aulis Strand, Von Phocis, vom Spartanerland, Von Asiens entlegener Küste, Von allen Inseln kamen sie, Und horchen von dem Schaugerüste Des Chores grauser Melodie, 
Der streng und ernst, nach alter Sitte, Mit langsam abgemeßnem Schritte, Hervortritt aus dem Hintergrund, Umwandelnd des Theaters Rund. So schreiten keine ird'schen Weiber, Die zeugete kein sterblich Haus!

Es steigt das Riesenmaß der Leiber Hoch über menschliches hinaus.

Ein schwarzer Mantel schlägt die Lenden, Sie schwingen in entfleischten Händen

Der Fackel düsterrote Glut, In ihren Wangen fließt kein Blut. Und wo die Haare lieblich flattern, Um Menschenstirnen freundlich wehn, Da sieht man Schlangen hier und Nattern Die giftgeschwollenen Bäuche blähn.

Und schauerlich gedreht im Kreise Beginnen sie des Hymnus Weise, Der durch das Herz zerreißend dringt, Die Bande um den Sünder schlingt. Besinnungsraubend, Herzbetörend Schallt der Errinyen Gesang, Er schallt, des Hörers Mark verzehrend, Und duldet nicht der Leier Klang:

»Wohl dem, der frei von Schuld und Fehle Bewahrt die kindlich reine Seele! Ihm dürfen wir nicht rächend nahn, Er wandelt frei des Lebens Bahn. Doch wehe, wehe, wer verstohlen Des Mordes schwere Tat vollbracht, Wir heften uns an seine Sohlen, Das furchtbare Geschlecht der Nacht!

Und glaubt er fliehend zu entspringen, Geflügelt sind wir da, die Schlingen 
Ihm werfend um den flüchtgen Fuß, Daß er zu Boden fallen muß.

So jagen wir ihn, ohn' Ermatten, Versöhnen kann uns keine Reu, Ihn fort und fort bis zu den Schatten Und geben ihn auch dort nicht frei.«

So singend, tanzen sie den Reigen, Und Stille wie des Todes Schweigen Liegt über'm ganzen Hause schwer, Als ob die Gottheit nahe wär'. Und feierlich, nach alter Sitte Umwandelnd des Theaters Rund, Mit langsam abgemeßnem Schritte, Verschwinden sie im Hintergrund.

Und zwischen Trug und Wahrheit schwebet Noch zweifelnd jede Brust und bebet Und huldigt der furchtbar'n Macht, Die richtend im Verborg'nen wacht, Die unerforschlich, unergründet Des Schicksals dunklen Knäuel flicht, Dem tiefen Herzen sich verkündet, Doch fliehet vor dem Sonnenlicht.

Da hört man auf den höchsten Stufen Auf einmal eine Stimme rufen: »Sieh da! Sieh da, Timotheus, Die Kraniche des Ibykus!« - Und finster plötzlich wird der Himmel, Und über dem Theater hin Sieht man in schwärzlichtem Gewimmel Ein Kranichheer vorüberziehn.

»Des Ibykus!« - Der teure Name Rührt jede Brust mit neuem Grame, Und, wie im Meere Well auf Well, So läuft's von Mund zu Munde schnell: 
»Des Ibykus, den wir beweinen,

Den eine Mörderhand erschlug!

Was ist's mit dem? Was kann er meinen?

Was ist's mit diesem Kranichzug?« -

Und lauter immer wird die Frage,

Und ahnend flieg'ts mit Blitzesschlage

Durch alle Herzen. »Gebet acht!

Das ist der Eumeniden Macht!

Der fromme Dichter wird gerochen,

Der Mörder bietet selbst sich dar!

Ergreift ihn, der das Wort gesprochen,

Und ihn, an den's gerichtet war.«

Doch dem war kaum das Wort entfahren,

Möcht' er's im Busen gern bewahren;

Umsonst, der schreckenbleiche Mund

Macht schnell die Schuldbewußten kund.

Man reißt und schleppt sie vor den Richter,

Die Szene wird zum Tribunal,

Und es gestehn die Bösewichter,

Getroffen von der Rache Strahl.

Friedrich Schiller, Sämtliche Gedichte und Balladen, herausgegebenvon

Georg Kurtscheid, Insel Verlag, Franfurt am Main, 2004, pp. 69-74

\section{Os grous de Íbico}

Para os jogos das quadrigas e dos cantos,

Que no Istmo de Corinto

As tribos gregas reúne alegremente,

Dirigiu-se Íbico, o amigo dos deuses.

Recebera a dádiva do canto,

Das doces canções, dos lábios de Apolo.

Assim peregrinava, com leve cajado,

Vindo de Regium, pelo deus inspirado.

Já os cumes altos de Acrocorinto

Alcança o olhar do peregrino,

E nos pinhais de Posídon 
Penetra com piedoso calafrio.

Nada se move à sua volta, apenas

Bandos de grous o acompanham,

Que em esquadrilhas cinzentas

Para o calor do Sul se encaminham.

Eu vos saúdo, bandos amigos!

Até ao mar vieram comigo,

Por bom augúrio vos tomo,

Como o vosso é o meu caminho.

Viemos de longe até chegar aqui,

E pedimos um tecto que nos acolha.

Que nos seja dada guarida,

Que o estrangeiro se livre da vergonha!

E, alegre, o passo apressa,

E vê-se no meio da floresta,

Lá, num apertado atalho, de súbito,

Barram-lhe o caminho dois assassinos.

Precisa de se preparar para a luta,

Mas logo baixa a mão, com desalento,

As cordas da lira tendera. Para a disputa,

A força do arco, nem por um momento.

Chama pelos homens, pelos deuses,

Não chega a salvador algum o seu lamento,

Por maior que seja o seu grito,

Aqui, não se avista nada de vivo.

»Então, terei que morrer aqui, abandonado,

Em solo estrangeiro, sem ser lamentado,

Perecer à mão de malvados,

Sem que ninguém acorra para ser vingado!«

E, gravemente atingido, por terra se prostrou

Então, sussurrando, o bando de grous passou,

Ele ouve, pois ver já não pode,

As vozes aterradoras ouvem-se perto.

»A vós, grous, que pairais no alto! 
Se mais nenhuma voz escutar, Chegue a queixa do meu assassínio! « Disse isto, e fechou-se o seu olhar.

O cadáver despido foi encontrado, E logo, embora de feridas sulcado, Reconheceu o anfitrião de Corinto Os traços que lhe são tão queridos. » Tenho que te voltar a ver assim, Eu que esperava, com a coroa de pinho, As frontes do poeta cingir, Iluminada pelo seu glorioso brilho!«

E todos ouvem com gemidos, Nas festas de Posídon reunidos ${ }^{1}$, De toda a Grécia a dor se apodera, Para todos os corações foi uma perda, E, precipitando-se para o Pritaneu ${ }^{2}$ O povo se dirige, impelido pela ignomínia, Para vingar o homem que morreu, Para, com o sangue, expiar, o assassino.

Mas onde o seu rasto descobrir No turbilhão das gentes a surgir, Atraídas pelos jogos, pelo seu esplendor, O que poderá revelar o pérfido autor?

Por traiçoeiros ladrões foi morto?

Acto de inveja de inimigo oculto?

Dizer só a Hélio é possível, Ele, que na terra, tudo torna visível.

1 Os Jogos Ístmicos eram celebrados de dois em dois anos, em honra de Posídon.

2 Edifício público das antigas cidades da Grécia que era o centro cívico e religioso da cidade. Era lá que se mantinha permanentemente aceso o fogo sagrado, dedicado à Héstia, deusa protectora da família e do lar. Era o local onde se reuniam os prítanes que representavam o povo. Era também o local onde os visitantes ilustres eram recebidos. 
Com passo atrevido, talvez passeie, Pela Grécia, agora mesmo, no seu meio, E enquanto a vingança o procura, Do seu atrevimento desfruta.

Na própria entrada do templo Atrevido, talvez se oponha aos deuses, Mistura-se em cada onda de gente Que se empurra para o teatro.

Pois empurram-se de banco em banco, Rompem quase as protecções do palco, De perto e longe aqui chegados, Pelos povos da Grécia aguardados, Como as ondas do mar bramindo, Num enxame de gente, o teatro se ergue, Curvando-se num arco, subindo Até chegar ao azul do céu.

Quem conta os povos, os estrangeiros

Que aqui se juntaram, quem os nomeia?

Da cidade de Cécrops ${ }^{3}$, das praias da Áulide

Da Fócida, das terras de Esparta,

Das costas distantes da Ásia,

Vieram das ilhas todas,

E escutam da tribuna

A terrível melodia do coro.

Austero e solene, ao costume antigo, Com passos lentos, bem medidos, Vindo do fundo, chega-se à frente, O círculo do teatro envolvendo, Não andam assim mulheres terrenas, Não as criou nenhuma casa de mortais!

Dos corpos a gigantesca massa

Para além do humano se eleva mais.

3 Primeiro rei da cidade de Atenas. 
Um manto negro esconde as ancas, Ondulam com mãos descarnadas

Com o archote vermelho de sequioso ardor,

Não corre sangue nas suas faces sem cor,

E onde ondulam docemente os cabelos,

Que se movem em torno das humanas frontes,

Vê-se serpentes e víboras

Que insuflam o abdómen de veneno.

E formando um terrível círculo, Começam a melodia de um hino, Que passa, o coração arrepiando, A horda aperta o criminoso, Atordoando os sentidos, perturbando

O coração, das Erínias soa o canto, Soa, a medula do ouvinte desgastando, $\mathrm{E}$ à lira não consente o som:

» Feliz o que de culpa e erro está livre Conserva a alma pura e juvenil!

Dele, na vingança, não nos podemos aproximar, Livre, nos trilhos da vida, pode caminhar.

Mas ai daquele, ai dele que cometeu, Furtivo, o grave crime do assassínio, Colamo-nos às suas plantas dos pés A terrível estirpe da noite!

E se ele, fugindo, tenciona escapar, Com asas lá estaremos, para lhe lançar A armadilha aos pés que querem fugir, Para que no chão tenha que cair. Assim, infatigavelmente, o caçaremos, Penitência alguma nos reconcilia, Até às sombras o perseguiremos, Não terá a liberdade que o alivia.«

Cantando assim, dançam, rodando E o silêncio, como o da morte rondando 
Sobre toda a casa paira, com todo o peso

Como se a divindade estivesse perto, E, em festa, segundo o costume antigo, Andam à volta do círculo do teatro, Com passos lentos, bem medidos,

Desaparecem no pano de fundo.

E, entre a ilusão e a verdade pairando, Treme, ainda em cada peito duvidando, E presta homenagem ao temível poder,

Que, julgando, no que se esconde, pode ver

O imperscrutável, o que não se alcança,

O novelo obscuro que o destino entrelaça,

No fundo do coração se proclama,

Mas da luz do sol se afasta.

Nos degraus mais altos então se escuta

Uma voz que, de repente, chama:

» Repara! repara, Timóteo,

Os grous de Íbico!« -

E o céu escurece subitamente,

E, por cima do teatro,

Vê-se, em enegrecido frémito,

Um bando de grous que passa.

» De Íbico!« - O nome eleito

Renovada dor acende em cada peito

E, como no mar, onda após onda,

Assim corre depressa de boca em boca:

» De Íbico, que lamentamos perder,

Que uma mão assassina matou!

O que é isto? O que quer dizer?

Que significa este bando de grous?« -

E, cada vez mais alto se interroga,

Pressentindo, como relâmpago, voa

Por todos os corações. » Escutai!

Este é o poder das Euménides! 
O piedoso poeta é vingado,

Diante de nós está o assassino!

Agarrem-no, o que disse a palavra,

E o outro a quem se dirigiu «.

A este, mal a palavra foi dita, Bem guardá-la no peito desejaria;

Em vão, lívida de medo, a boca

Depressa confessa a sua culpa.

Agarram-no e para o juiz o arrastam,

A cena em tribunal se transforma,

E os criminosos confessam,

Atingidos pelo raio da vingança.

Tradução de Maria do Sameiro Barroso

no me entregues

tristísima medianoche al impuro mediodía blanco

Alejandra Pizarnik ${ }^{4}$

Em 26 de Junho de 1797, Schiller enviou a Goethe a balada, $O$ anel de Polícrates, que terminara dois dias antes, como contraponto à balada $O s$ grous de Íbico que tinha planeado ${ }^{5}$. Seria publicada no Musenalmanach (Almanaque das Musas) do ano seguinte. A ideia de tratar este assunto surgira de um antigo provérbio que referia os grous de Íbico numa conversa com Goethe, em Junho desse ano. Embora a Goethe tivesse agradado imediatamente a ideia, foi Schiller quem acabou por a escrever.

Pediu ajuda a Karl August Böttiger, professor, filólogo e especialista em Antiguidade Clássica. Schiller obteve dele informações de uma tradição segundo a qual Íbico teria sido assassinado num teatro. As fontes em que se baseou foram a Anthologia Graeca, Plutarco, Erasmo e o ornitólogo Aldovandri.

4 Alejandra Pizarnik, Antologia Poética (edição bilingue), O correio dos navios, Porto, s. data, p. 47, Poema $O$ coração do que existe.

5 Gero von Wilpert, Schiller-Chronik. Sein Leben und Schaffen, Mit 12 Abbildungen, Reclam, Stuttgart, 1958 (reimpressão de 2000), p. 235. 
Wilhelm von Humboldt também contribuiu para a escrita da balada, pois a sua tradução das Euménides de Ésquilo servira de base para a escrita do canto das Erínias da balada ${ }^{6}$.

A 17 de Agosto, enviou a balada a Goethe, confessando que esta lhe tinha encontrado mais dificuldades do que imaginara. Os dois pontos mais importantes foram, em primeiro lugar, a dificuldade de configurar uma continuidade narrativa que não se encontra na fábula antiga; em segundo lugar foi a de criar um ambiente no qual conseguisse fazer actuar os efeitos utilizados. Mas, diz, pensa ter conseguido ultrapassar essas dificuldades. Agradar-lhe-ia que esses pontos coincidissem com os de Goethe ${ }^{7}$. Em Setembro, Schiller fez algumas alterações, por sugestão de Goethe ${ }^{8}$. Numa carta que lhe escreveu a 14 de Setembro, tendo já terminado a balada, transmite-lhe o agrado que Böttiger, o especialista clássico, manifestara, face ao resultado obtido ${ }^{9}$.

Sobre Íbico, sabe-se que nasceu em Régio, na Calábria. Está associado à ilha de Samos, onde foi protegido por Polícrates, em cuja corte, segundo a Suda, terá vivido na década de 60 do século VI a.C. É considerado o primeiro cultor do epinício, ode triunfal dedicada aos vencedores dos jogos helénicos ${ }^{10}$. As datas apontadas para o seu nascimento e morte são c. 576c.525. Escreveu em dialecto dórico. Diz-se que inventou a sambuca, instrumento musical semelhante à cítara e que foi assassinado por ladrões ${ }^{11}$.

Sobre Polícrates, escreveu:

Também tu, ó Polícrates, terás nome imorredouro, Graças ao meu canto e à minha fama ${ }^{12}$.

${ }^{6}$ Karl Pestalozzi, Die sugestive Wirkung der Kunst, in Org. Norbert Oellers, Interpretationen, Gedichte von Friedrich Schiller, Reclam, Stuttgart , 1996, pp. 222223.

7 Schillers Briefe in zwei Bänden, National Forschungs uns Gedenstätten der Klassischen Deutschen Literatur, Berlim, 1982, Band II, p. 147.

8 Gero von Wilpert, Schiller-Chronik, p. 237.

9 Schillers Briefe in zwei Bänden, p. 152.

10 Frederico Lourenço, organização e tradução Poesia Grega de Álcman a Teócrito, Livros Cotovia, Lisboa, 2006, p. 45.

11 Friedrich Schiller, Gedichte, Auswahl und Anmerkungen von Norbert Oelers, Philipp Reclam jun., Stuttgart, 2001, p. 171.

12 Frederico Lourenço, Poesia Grega de Álcman a Teócrito, p. 49. 
Os alexandrinos editaram os poemas de Íbico em sete livros. Parece ter cultivado não só a ode coral, mas também a poesia monódica ${ }^{13}$.

O poeta parece ter tido uma relação muito especial com os pássaros. A balada enquadra a ida do poeta aos Jogos Ístmicos e encena o seu assalto por dois criminosos, e, antes de morrer, o testemunho e o pedido de vingança que faz chegar aos grous que o vinham a acompanhar. No centro do poema, encontra-se a Némesis, o acto criminoso que é necessário vingar. No entanto, os grous não são aves do destino. Esta capacidade de escutar o poeta e de levar a cabo a sua vingança é imaginação poética. O importante foi criar a associação: Íbico - grous - assassínio - vingança. No centro está a representação teatral do canto do coro das Erínias ${ }^{14}$.

Plutarco (De Garrulitate, xiv) relata a sua morte da seguinte maneira: quando estava perto de Corinto, o poeta foi ferido mortalmente por ladrões. Já moribundo, viu passar um bando de grous que incitou a vingar a sua morte. Os ladrões, que eram de Corinto, dirigiram-se para lá para ver a representação do teatro. Os grous apareceram. Ao vê-los, num gesto de burla, um dos ladrões gritou: Olhai, os grous de Íbico! E, assim, eles mesmos forneceram a pista para a sua detenção pelo crime cometido.

A frase "os grous de Íbico" transformou-se num provérbio entre os gregos para a descoberta de um crime por intervenção divina ${ }^{15}$.

Para dar consistência dramática à lenda, Schiller tirou partido da peça de teatro. O drama antigo a que alude surgira a partir das festas do culto de Dioniso, nas quais havia danças festivas, e cânticos de coros, acompanhados pela música da flauta ou da cítara. Mais tarde surgiram versos, intercalados entre o coro e a actuação dos actores ${ }^{16}$.

Schiller soube criar uma intensa pressão psicológica, criada pelo reconhecimento do cadáver, pelo lamento colectivo da sua morte e finalmente, pela actuação sobrenatural das Erínias, as divindades nocturnas que fizeram com que os assassinos se revelassem, quando o bando de grous sobrevoou o teatro.

13 Maria Helena Ureña Prieto, Dicionário de Literatura Grega, Editorial Verbo, Lisboa/São Paulo, 2001, 246.

14 Karl Pestalozzi, Die sugestive Wirkung der Kunst, pp. 228-231.

15 http://sites.google.com/site/liricamonodica/ibico-y-anacreo.

16 Friedrich Schiller, Gedichte, Auswahl und Anmerkungen von Norbert Oelers, Philipp Reclam jun., Stuttgart, 2001, pp. 171-172 
Schiller era um excelente conhecedor das emoções humanas. Embora os seus escritos médicos tivessem ficado na sombra da sua obra literária, Schiller, enquanto jovem médico, revelava-se, apesar das suas especulações, mal aceites no seu tempo, um psicólogo ou um psiquiatra avant la lettre, antecipando a medicina psicossomática ou intuindo uma psicologia materialista, apesar do pendor metafísico, patente nas teses ${ }^{17}$.

Sobre as baladas, que, a partir da forma popular, ambos elevaram à grande poesia, Goethe escreveu mais tarde:

Balladen. Ich verdanke sie größenteils Schillern, der mich dazu trieb, weil er immer etwas Ich hatte sie alle schon seit vielen Jahren im Kopf, sie beschäftigten meinem Geist als anmutige Bilder, als schöne Träume, die kamen und gingen und womit die Phantasie mich spielend beglückte ${ }^{18}$.

(Baladas. Agradeço-as, na sua maior parte, a Schiller, às quais me incitou, porque precisava sempre de algo de novo para as suas Horas. Já as tinha todas na cabeça, há muitos anos, ocupavam o meu espírito como imagens estimulantes, como belos sonhos, que vinham e iam e com as quais a fantasia, brincando comigo, me alegrava).

E, em carta dirigida a Körner, referindo-se a Goethe, Schiller escreve:

Er... will diese Gedichte als eine neue, die Poesie erweiternde Gattung angesehen wissen ${ }^{19}$.

(Ele... quer saber que estes poemas são encarados como um novo género alargado da poesia.).

Esta balada de pendor narrativo, inspirado no autor do fragmento:

Quando a gloriosa, insone madrugada desperta os rouxinóis ${ }^{20}$, que cantou os pássaros e se confiou aos grous, continuou a congregar as forças poéticas. Séculos depois da sua morte, Friedrich Schiller, cujo jubileu dos 250 anos do seu nascimento (1759-1805) se comemora este ano,

17 Wolfgang Riedel. Wolfgang Riedel, Die Anthropologie des jungen Schiller, Zur Ideengeschichte der medizinischen Schriften und der "Philosophischen Briefe", Königshausen \& Neumann, 1985, Würzburg, pp. 3-5.

18 Goethe, in Brief an Eckermann, 14,3,1830, apud Hrsg. Richard Dobel, Das Lexicon der Goethe-Zitate, Patmos Verlag, Albatros Verlag, Düsseldorf, 2002, p. 319.

19 Ernst Lautenbach, Lexicon Schiller Zitate aus Werk und Leben, Iudicium Verlag, München, 2003, An Körner, Jena, 27.4.1798, p. 342.

20 Tradução de Maria Helena Rocha Pereira, in Helade, Faculdade de Letras, Universidade de Coimbra, Instituto de Estudos Clássicos, 1990, p. 114. 
consubstanciou, em Íbico, não só o triunfo da justiça, mas o próprio triunfo da poesia.

MARIA DO SAMEIRO BARROSO 